\title{
Adolescents' associations between travel behaviour and environmental impact: A qualitative study based on the Norm-Activation Model
}

Møller, Mette; Haustein, Sonja; Bohlbro, Marie S.

Published in:

Travel Behaviour and Society

Link to article, DOI:

10.1016/j.tbs.2017.12.005

Publication date:

2018

Document Version

Peer reviewed version

Link back to DTU Orbit

Citation (APA):

Møller, M., Haustein, S., \& Bohlbro, M. S. (2018). Adolescents' associations between travel behaviour and environmental impact: A qualitative study based on the Norm-Activation Model. Travel Behaviour and Society, 11, 69-77. https://doi.org/10.1016/j.tbs.2017.12.005

\section{General rights}

Copyright and moral rights for the publications made accessible in the public portal are retained by the authors and/or other copyright owners and it is a condition of accessing publications that users recognise and abide by the legal requirements associated with these rights.

- Users may download and print one copy of any publication from the public portal for the purpose of private study or research.

- You may not further distribute the material or use it for any profit-making activity or commercial gain

- You may freely distribute the URL identifying the publication in the public portal 
Adolescents' associations between travel behaviour and environmental impact: A qualitative study based on the Norm-activation Model

Mette Møller*,a, Sonja Haustein ${ }^{\text {a }}$, Marie S. Bohlbro

* Corresponding author: mette@dtu.dk

${ }^{a}$ Technical University of Denmark, Department of Management Engineering, Diplomvej, Bygning 371, room, 230, DK-2800 Kgs. Lyngby. 


\section{Adolescents' associations between travel behaviour and environmental impact: A qualitative study based on the Norm-Activation Model}

\section{Abstract}

The negative environmental impact of car-dependent daily transport is well known. Young people of today are the potential drivers of the future and their mode choice will influence the environment for many years. This study explores the associations drawn between daily transport and environmental impact among 15-year-old Danish adolescents. We conducted 50 in-depth interviews and analysed them using a data-driven inductive thematic approach. We interpret differences in pro-environmental awareness and engagement on the background of the NormActivation Model (Schwartz, 1977). Based on their personal norm and the denial of consequences and responsibility of own behaviour, we identified five sub-groups of adolescents called Environmentalists, Pragmatics, Indifferent, De-emphasisers, and Deniers. Results indicate a need for measures to increase adolescents' awareness and acceptance of daily transport as a relevant issue in relation to sustainability. Such measures should include tangible feedback in a daily context while taking different coping strategies with regard to climate change into account.

\section{Introduction}

The fundamental societal value of transport-related mobility is generally recognised (e.g. Banister et al., 2012). However, developing a transport system that meets needs at the individual as well as at the societal level, while minimising the negative side effects related to $\mathrm{CO}_{2}$ emissions (e.g. Chapman, 2007; European Commission, 2011; Stanley et al., 2011), congestion (e.g. David \& Foucart, 2014; De Palma \& Lindsay, 2011; Hysing et al., 2014), and public health (e.g. Bauman et al., 2011; Sælensminde, 2004; Wegman et al., 2012) remains a major challenge. This challenge cannot be met with technological improvements alone but also requires the change of individual travel behaviour. Reducing private car use is a key issue here, but as indicated by Tranter and Sharpe (2012) there is a need for more efficient ways to motivate potential future drivers to choose environmentally friendly modes. The adolescents of today are the potential drivers of the future. They constitute a target group of key relevance regarding long-term efforts to reduce the negative environmental impact of daily transport, and are therefore the focus of this study.

Adolescents are in a life phase of change towards adult life, including for example increased independent mode choice, independent living and educational choices, and therefore face a window of receptiveness that can influence their future behaviour in the direction of sustainable transport (Underwood et al., 2014; Verplanken et al., 2008). The importance of laying the foundations of sustainable transport behaviour during adolescence is further supported by studies indicating that values supporting car-based mode choices are adopted early in life (Collin-Lange, 
2014) and that adults' mode choices are influenced by past experiences and socialisation (Haustein et al., 2009). When people have established their (car) identity, threats to this identity can be a barrier to behaviour change (Murtagh et al., 2014). With regard to adolescents, the majority of studies of sustainable mobility focus on recent changes in travel behaviour (e.g. Kuhnimhof et al., 2011) or intentions regarding future travel behaviour (e.g. Line et al., 2012; Sigurdardottir et al., 2013).

A stagnation or reduction in kilometres driven per-capita has been reported in some European countries (Kuhnimhof et al., 2013) along with reduced licensing among youth (Delbosc \& Currie, 2013; Hjorthol, 2016). Similarly, reduced car travel of young people, in particular males, has been observed in the United States along with delayed licensing (Coogan, Nygaard, \& Weinberger, 2017). Contradictory trends have also been identified, including increased car use as passenger among children in Denmark, Finland, Great Britain, and Norway (Fyhri et al., 2011), as well as strong intentions to obtain a licence and own a car among pre-licensed adolescents (Sigurðardóttir, Kaplan, \& Møller, 2014; Sigurðardóttir et al., 2013). Thus, despite a possible car peak, particularly in the younger generation (e.g. Frändberg \& Wilhelmson, 2011; Kuhnimhof, 2012; Newmann \& Kenworthy, 2011), there is still a significant potential to reduce future transport-related $\mathrm{CO}_{2}$ emissions.

Generally, adolescents' awareness and their appraisal of threats to the environment is high (OECD, 2009) and not limited to local issues (Busse \& Menzel, 2014). However, their awareness of environmental problems is only slightly associated with their own everyday behaviour (e.g. Davison et al., 2003; Toth et al., 2013); the problems are perceived as something “out there” rather than an issue they can relate to (Loughland et al., 2003). Yet, in a German study including children and adolescents, changes in mobility behaviour (esp. reduced car use) was the most often considered activity against climate change (Klöckner, Beisenkamp, \& Hallmann, 2010a).

Based on these contradictory results, we look into the associations drawn between daily transport and environmental impact among 15-year-old Danish adolescents, taking into account differences with regard to gender and residential location. As in the adult population, a gender difference regarding environmental attitudes and behaviours has been identified among youth (e.g. Loughland et al., 2002; 2003; OECD, 2009; Tuncer et al., 2005; Uitto, Juuti, Lavonen, Beyman, \& Meisalo, 2011). Young women are more likely to see the environment as an integrated part of their lives, ascribe themselves more responsibility towards action, and are more pessimistic about possibilities for change in the future. By contrast, young men have greater knowledge about environmental issues, feel less responsible and are more optimistic regarding sustainability in the future. The pattern that women express more concern and men have more knowledge has been found in a couple of studies (see Gifford \& Nilsson, 2014). However, a recent study with focus 
on transport and climate change neither found a gender difference with regard to knowledge on transport-related $\mathrm{CO}_{2}$ emissions nor with regard to concern for climate change (Waygood \& Avineri, 2016). In addition, the study revealed that both genders are aware of the link between mode choice and $\mathrm{CO}_{2}$ emissions but lack more specific knowledge, such as the influence of vehicle occupancy rate on the amount of emissions.

With regard to residential location, conflicting results have been found in terms of living in rural versus urban areas (see Gifford \& Nilsson, 2014). However, adults living in cities appear more concerned with climate change and sustainability than people living in rural areas, particularly with regard to transport-related issues such as air pollution (e.g. Berenguer et al., 2005). This is in line with the assumption that proximity to problem sites results in higher levels of environmental concern (Gifford \& Nilsson, 2014).

When focussing on young people and residential location, only minor differences between rural and urban residents have been identified. Uitto et al. (2011) found that rural residents aged around 15 years show less interest in environmental issues than their counterparts in more densely populated areas. Bogner and Wiesman (1997) found neither a difference in environmental behaviour nor in environmental attitudes between 11-16-year-old rural versus (sub-)urban residents. However, they found a higher discrepancy in rural pupils' verbal and actual environmental commitment; rural pupils behaved more environmentally friendly than verbally expressed.

A useful framework to explain when and why environmental awareness results in concrete action has been provided by the Norm-Activation Model (NAM; Schwartz, 1977; Schwartz \& Howard, 1981) and its application to travel mode choice (e.g. Bamberg, Hunecke, \& Blöbaum, 2007; Klöckner \& Matthies, 2004). We chose this model as a theoretical framework of our study as our data clearly relate to central processes described in the model, such as the denial of consequences and responsibilities.

According to the NAM, the first step towards engagement in a prosocial behaviour is the awareness of a need (AN). If a person is not aware that car use is harmful for the environment, moral norms will not be activated. Knowledge is thus a precondition for the activation of a normbased decision process. Individuals must further be aware of the consequences (AC) of their own behaviour (e.g., the positive or negative environmental impact of their transport choices) and feel responsible for the consequences of not acting prosocially (ascription of responsibility, AR).

In addition, people must identify particular actions to relieve the problem (outcome efficacy; OE). Steg and Groot (2010) have broadened the concept of OE to perceiving the ability to control the problem. In case of large-scale problems, such as reducing transport-related emissions, OE strongly depends on the expectations that others will also act pro-socially (Steg \& Groot, 2010). 
Finally, people must perceive the ability to act prosocially (e.g. use environmentally transport modes), which refers to the construct of perceived behavioural control (PBC) of the Theory of Planned Behaviour (Ajzen, 1991). In case of children and adolescents, parental rules and choices may restrict PBC.

Given that preconditions with regard to AN, AC, AR, OE, and PBC are fulfilled, individuals' personal norms (PN) will be activated. $\mathrm{PN}$ is defined as the intrinsic feeling of moral obligation to behave in accordance with the person's individual value system (Schwartz, 1977), for example, to feel obliged not to use the car as it harms the environment. In addition to PN, social norms (SN) are also considered in the NAM, representing the expectations of significant others. NAM regards PN as the central predictor of behaviour.

However, the activation of PN does not automatically lead to moral behaviour. For individuals who are aware of the negative impacts of car use, the evaluation of personal costs, such as reduced convenience or time, may weigh higher than feelings of guilt or shame when not acting in accordance with PN or SN, respectively. A strategy to avoid negative feelings can be the denial of the harmful consequences of car use (AC) or the denial of the personal responsibility for the negative consequences (AR), for example by stating that it is the responsibility of the car industry or politicians to reduce the car emissions. Thereby the situation will be re-defined, so that the person no longer feels obliged to follow the moral norm (PN). In studies on how children, adolescents and adults cope with climate change, de-emphasising the threat and denial of guilt have been identified as coping strategies that are related to a lower degree of environmental efficacy, lower engagement in pro-environmental behaviours (Homburg, Stolberg, \& Wagner, 2007; Ojala, 2012; 2013), and reduced action knowledge (Klöckner et al., 2010a), which is in line with the assumptions of the NAM.

We use the NAM as a framework for the interpretation of our results. In the discussion, we focus on the identification of targeted interventions to support environmentally friendly transport behaviours at early stages of independent mode choice. When suggesting interventions, we make use of Bamberg's Stage Model of Self-Regulated Behavioural Change (Bamberg, 2013; 2014), which integrates central constructs and assumptions of the NAM and TPB into the Transtheoretical Model (Prochaska \& DiClemente, 1983). Bamberg's model differentiates four stages of behavioural change (predecisional, preactional, actional, postactional) and stresses the need to develop interventions that adequately address the needs of persons in a specific stage.

\section{Methodology}

\subsection{Procedure and participants}


We used in-depth interviews as the method of data collection. The 50 interviews took place in June and July 2011 at the interviewees' location of convenience. We sampled the participants among 891 15-year-old adolescents who participated in a national online survey on travel behaviour (see Sigurðardóttir et al., 2013). Statistics Denmark recruited participants for the survey as a representative sample, and as part of the survey, participants gave their consent to participate in future studies. For the present study, sampling of participants was random but based on two criteria: 1) equal number of males and females, 2) representation of different residential areas. Six participants lived in Copenhagen, the capital of Denmark, 30 lived in smaller cities $(10,000-$ 100,000 inhabitants), and 14 lived in rural areas ( $<10,000$ inhabitants).

None of the participants had a driving licence yet, as the licensing age is 18 in Denmark, but all intended to get a licence at some point. At least one car was available in the family of all adolescents. Furthermore, all participants had a bike and access to public transport. Table 1 provides an overview of the main transport mode for daily school transport by type of residential location and compares it with data from the national Danish travel survey (TU, 2006-2017). The comparison shows that the mode choice for the complete sample is representative for Danish 15year-olds. However, when breaking the small numbers down to residential location, we find for example that cycling levels in our sample are higher in the rural areas while they are lower in Copenhagen and smaller cities than what would be representative. Regional differences should thus be interpreted with caution.

In order to avoid biasing the results we did not explicitly state our interest in their associations between daily transport and environmental issues. Instead, we informed the participants that the purpose of the study was to collect in-depth information about travel behaviour among youth. According to Danish law, parental consent is not needed for persons aged 15 or older, and parents were therefore not asked for permission in relation to this study. Due to the topic of the study, there was no need for approval by an ethics committee according to Danish law. 
Table 1: Main mode for daily school transport of study participants (sample) and 15-year-old participants of the national Danish travel survey (TU, 2006-2017).

\begin{tabular}{|c|c|c|c|c|c|c|c|c|c|c|c|c|c|c|c|c|}
\hline \multirow{3}{*}{$\begin{array}{l}\text { Transport } \\
\text { mode }\end{array}$} & \multicolumn{4}{|c|}{ Copenhagen } & \multicolumn{4}{|c|}{ Smaller city } & \multicolumn{4}{|c|}{ Rural area } & \multicolumn{4}{|c|}{ Total } \\
\hline & \multicolumn{2}{|c|}{ Sample } & \multicolumn{2}{|c|}{ TU } & \multicolumn{2}{|c|}{ Sample } & \multicolumn{2}{|c|}{ TU } & \multicolumn{2}{|c|}{ Sample } & \multicolumn{2}{|c|}{ TU } & \multicolumn{2}{|c|}{ Sample } & \multicolumn{2}{|c|}{ TU } \\
\hline & $n$ & $\%$ & $n$ & $\%$ & $n$ & $\%$ & $n$ & $\%$ & $n$ & $\%$ & $n$ & $\%$ & $n$ & $\%$ & $n$ & $\%$ \\
\hline Bicycle & 2 & 33 & 61 & 52 & 12 & 40 & 87 & 56 & 7 & 50 & 78 & 40 & 21 & 42 & 284 & 42 \\
\hline $\begin{array}{l}\text { Public } \\
\text { transport }\end{array}$ & 1 & 17 & 21 & 25 & 9 & 30 & 17 & 10 & 1 & 7 & 71 & 41 & 11 & 22 & 158 & 24 \\
\hline Walking & 2 & 33 & 22 & 31 & 3 & 10 & 47 & 27 & 5 & 36 & 17 & 8 & 10 & 20 & 130 & 18 \\
\hline $\begin{array}{l}\text { Car (driven } \\
\text { by parents) }\end{array}$ & 1 & 17 & 1 & 2 & 5 & 17 & 14 & 7 & 1 & 7 & 14 & 11 & 7 & 14 & 81 & 12 \\
\hline Moped & 0 & 0 & 2 & 3 & 1 & 3 & 0 & 0 & 0 & 0 & 0 & 0 & 1 & 2 & 4 & 0 \\
\hline Other & 0 & 0 & 2 & 2 & 0 & 0 & 0 & 0 & 0 & 0 & 3 & 1 & 0 & 0 & 33 & 4 \\
\hline Total & 6 & 100 & 109 & 100 & 30 & 100 & 165 & 100 & 14 & 100 & 183 & 100 & 50 & 100 & 690 & 100 \\
\hline
\end{tabular}

The interviews were framed by a semi-structured interview guide as described by Gaskell (2000), which allowed the participants to express their individual perspectives of the subject through narratives based on their own lives and experiences (Jovchelovitch \& Bauer, 2000). The daily life of the adolescents was the point of departure for exploration of the association they draw between their daily transport demand and the environmental impact. As a starting point, all interviewees were asked to tell about whom they live with and which transport modes they have and use in everyday life. With supporting questions, this provided a detailed insight into the adolescents' and their household members' regular activities, current and future transport choices, and what role environmental reasons played for these choices and in general. The interviews lasted on average 40 minutes. Verbatim transcripts were prepared, excluding paralinguistic characteristics. For the purpose of this paper, we translated relevant quotes from Danish to English.

\subsection{Analysis}

For data analysis, we applied a data-driven inductive thematic approach based on Braun and Clarke (2006). The analysis included four steps: First, we read and reread the transcripts to become familiar with the data. Second, we coded the data initially. Third, we identified themes in accordance with the Norm-Activation Model (AN, AC, PBC, PN, OE) as this appeared as the most fitting framework after step 1 and 2. In this process, PN played the most central role as participants were divided into subgroups based on their level of personal norm as expressed in the interview as a whole. This categorisation was done independently by two of the authors. In case of differences in the allocation to groups (happened in seven cases), the final coding was 
done in a consensus-oriented process. The final coding also included the derivation and adaptation of additional sub-categories (in case of persons with low PN). In addition, we analysed the adolescents' perspectives of possible solutions to transport-related environmental problems in the future. The fourth and final step of the analysis included exploration of potential differences based on living location and gender as well as relations between the different themes. The analysis was performed at the semantic level based on explicit statements and reflections. We used the software NVivo 10 to support the analysis.

\section{Results}

Table 2 provides an overview of the coding in relation to the constructs of the NAM and in relation to adolescents' reflections on interventions to support sustainable transport in the future. The remainder of this section presents the results for each category.

Table 2: Interview content and coding

\begin{tabular}{|c|c|c|}
\hline Content & Category & Sub-category \\
\hline \multirow[t]{3}{*}{ Awareness of Need (AN) } & General & Energy consumption \\
\hline & & Industrial pollution \\
\hline & Transport & Transport pollution \\
\hline \multirow[t]{4}{*}{ Awareness of Consequences (AC) } & General & Parents' economy \\
\hline & & Environment \\
\hline & Transport & Mode choice \\
\hline & & Distances \\
\hline \multirow[t]{4}{*}{ Perceived Behavioural Control (PBC) } & Parents & $\begin{array}{l}\text { Parents' rules supporting independent } \\
\text { travel }\end{array}$ \\
\hline & & $\begin{array}{l}\text { Parents' rules restricting independent } \\
\text { travel }\end{array}$ \\
\hline & & Parent's time schedule \\
\hline & Trip conditions & Distance, time, weather \\
\hline \multirow[t]{5}{*}{ Personal Norm (PN) } & High & Environmentalists \\
\hline & Medium & Pragmatics \\
\hline & Low & Indifferent \\
\hline & & De-emphasisers \\
\hline & & Deniers \\
\hline \multirow[t]{4}{*}{ Outcome Efficacy (OE) } & High & Can make a difference \\
\hline & & $\begin{array}{l}\text { Can make a difference, in particular } \\
\text { when others join }\end{array}$ \\
\hline & Low & Cannot make a difference \\
\hline & & $\begin{array}{l}\text { Cannot make a difference, everyone } \\
\text { would have to join }\end{array}$ \\
\hline \multirow[t]{6}{*}{ Intervention } & Type & Technology \\
\hline & & Behaviour \\
\hline & Level & Individual level \\
\hline & & Societal level \\
\hline & Implementation & Mandatory \\
\hline & & Voluntary \\
\hline
\end{tabular}

\subsubsection{Awareness of need (AN) and awareness of consequences (AC)}

The analyses revealed a general awareness of the possible environmental impacts of behaviours of daily life, but only a limited awareness and reflection of possible impacts from 
interviewees’ own daily transport. Both, general awareness and transport-related awareness was more pronounced among females than males.

Aspects related to energy consumption, such as turning off the lights when leaving a room and not leaving the computer or television in stand-by mode, were frequently and promptly mentioned as ways to contribute positively to a sustainable environment on a daily basis.

"My computer is always turned off and the television is also only turned on if I need it. And I turn off the lights; it is just something we have been taught since childhood, to turn off the lights when leaving a room”, (Angela ${ }^{1}$, AN, General, Energy consumption).

Adolescents generally expressed a positive attitude towards energy saving behaviours, but the performance of those behaviours was only partly motivated by awareness of the environmental consequences of the behaviours. By contrast, a parental request to reduce the electricity bill was a key motivating factor.

Other aspects mentioned in relation to a sustainable environment were recycling, animal welfare, organic food, and child labour. The participants frequently mentioned environmental issues and sustainability as being a part of the school curriculum and thus school education probably contributed to adolescents' awareness of need and consequences. However, although environmental issues are included in the Danish school curriculum large variations depending on the individual school and teacher exist, as it is not a compulsory part of the curriculum.

Compared to the prompt mentioning of daily energy consumption, the adolescents made few spontaneous references to daily transport, and the awareness of a need for action in relation to daily transport appeared to be low. Nevertheless, they did express some awareness of the environmental impact of daily transport in statements regarding mode choice and travel distance as well as the relation between both. Furthermore, they generally viewed the car as the least sustainable mode choice for daily travel, and suggested the bicycle as a sustainable alternative for short distances, and public transport as a sustainable choice for longer distances. In single cases, a more advanced awareness of environmental consequences of daily transport was expressed when some adolescents questioned public transport as an environmentally friendly mode choice based on personal experiences with public buses with many empty seats.

\footnotetext{
${ }^{1}$ Names changed to anonymise the data.
} 
"If I am the only one on the bus, I think - what good does this do to the environment? A large bus with only one passenger is worse than a small car loaded with people. I just don't know what to think”, (Marie, AC, Transport, Mode choice).

Similarly, electric cars were generally associated with sustainability, although some adolescents questioned this by referring to the need to charge car-batteries.

All in all, adolescents' awareness of a need with regard to daily transport appeared to be low, even though some awareness of environmental consequences of transport choices was expressed.

\subsubsection{Mode choice and perceived behavioural control (PBC)}

With regard to PBC, adolescents differed in the extent to which they perceived their current transport choices to be restricted and by which factors they were restricted. About half of the adolescents $(n=26)$ described that they could choose their mode of transport themselves, while the other half felt to a smaller $(n=10)$ or larger extent $(n=14)$ that mode choice was not under their control. Among those who felt free in their choices, many travelled by bike and stressed the freedom and independence of this mode - both for themselves as well as for their parents who then did not have to give them a lift. Getting exercise and fresh air as well as saving time and money were also among the reasons for choosing the bike, while environmental reasons did not play a significant role.

Those who felt restricted in their mode choice often described specific rules by their parents. In most cases, these rules support independent travel:

"Well, my father always meant: when I manage to get out somewhere, I also manage to get home again”, (Freja, AR, Parents’ rules supporting independent travel).

Attitudes towards getting or not getting a lift were diverse: While many appreciated it because of convenience, others preferred to be independent or found it embarrassing to be driven by their parents.

Rules restricting independent travel related for example to travelling alone in the evening/in the dark or taking the bike when under the influence of alcohol. These as well as long distances and limited accessibility were also the conditions often mentioned for getting a lift by the parents.

Apart from specific occasions when parents offered or insisted on giving a lift, it was mainly the parents' time schedule and working times that determined whether adolescents could get a lift or not (in Denmark usually both parents work full-time). Overall, adolescents appeared quite free in their travel choices. As external factors that made it difficult to choose environmental transport 
modes, weather conditions were sometimes mentioned for cycling and that it was too complicated or inconvenient, too time consuming and too expensive to use public transport.

\subsubsection{Personal norm (PN) and outcome efficacy $(\mathrm{OE})$}

We identified three levels of personal norm and/or norm activation based on the interview as a whole: high, medium and low. The fewest adolescents $(n=12)$ expressed a high personal norm to make environmentally friendly transport choices, 17 a medium personal norm, and 21 expressed a low personal norm or norm activation.

Adolescents with a high personal norm in relation to transport choices showed an explicit attempt to prioritise environmental behaviours in general. We thus called this sub-group Environmentalists. These adolescents considered costs at the individual level, such as additional travel time or inconvenience, to be a secondary issue:

"I think quite a lot about the environment, and I try to do something for the environment, and yes, if it wasn't for the environment, then I can't see why I shouldn't have a car, then it would be fine to have a car. But if it damages the environment, well then I can easily live without it", (Charlotte, PN, High, Environmentalist).

Despite their expressed pro-environmental norms, pragmatic car attitudes were predominant within this group (e.g., that the car should be fuel-efficient and/or be practical and not too expensive). Thus, Environmentalist were not generally negative about cars. Actually, all of them expected to acquire a driving licence and most of them also expected to own a car at some point later in life (e.g. when having a family). Some also acknowledged the expressive function of a car and had a clear vision about their dream car:

"We have a really old car and we do not care about cars, so that it should be the newest new car. For us, it is just that we need to have a car and then it should be as cheap as possible. (...) well, when you ask me about my dream car, a retro Fiat 500 or a Mini Cooper. That's not a practical family car or anything like that but - that is just dream (...) it's is simply such a beautiful car (...) I like that retro style and that it is a bit different, so that one stands out in that way”, (Gitte, PN, High, Environmentalist).

Environmentalists also expressed a moral obligation to behave in a way that does not reduce prospects for future generations: 
"They say that the world is coming to an end, and there won't be any polar bears and everything... due to climate changes. This will be bad, maybe not for my generation and the next generation but then maybe for my grandchildren. And one has to consider that, too.", (Ditte, PN, High, Environmentalist).

This moral obligation was partly based on trust in the accumulated effects of individual contributions across time and space:

"I know that it [my behaviour] doesn't save the world, but it provides a contribution in the right direction, particularly if one does it, maybe, throughout life", (Valdemar, OE, High, Can make a difference).

While not all interviews contained passages that allowed for a classification with regard to the level of outcome efficacy, all Environmentalists that could be classified expressed a high level of outcome efficacy, either only by stating that their behaviour could make a difference, or by emphasising the need to convince others to make the contribution even bigger:

"Yes, my behaviour makes a difference, and if everyone does something, it suddenly makes a big difference”, (Gitte, PN, High, Environmentalist).

A medium personal norm was reflected in a pragmatic approach framed in the context of daily life, emphasising the need to not only consider possible environmental impact but to also take individual costs such as additional travel time or inconvenience into consideration. The relevance of considering environmental impact in relation to mode choice for daily travel was thus recognised, but in the context of a busy daily life involving long distances, tight schedules, or similar challenges they believed that prioritising convenience over environmental impact was appropriate:

"One should take the bike to nearby destinations. If you are going far away, then I think it is okay to take the car, but you should of course try to save it, the environment I mean.”, (Bo, PN, Medium, Pragmatist).

On each occasion, mode choice should thus be based on an individually performed cost-benefit analysis, taking the life-context and individual needs into consideration. If this turned out in 
favour of an environmentally friendly mode, such as choosing the bus instead of the car in a situation with limited parking spaces, the positive environmental influence was perceived as a positive, yet secondary, advantage:

"Then you do something good while it also becomes easier for yourself. So it is win-win.", (Anders, PN, Medium, Pragmatist).

With regard to outcome efficacy, the results related to Pragmatists were mixed: a bit more than half felt that their behaviour could make a difference, in particular when others contributed as well.

"I believe I can make a difference, but not alone (...). I try to ignore that not everybody does it (behave in an environmentally friendly way). If we all wait for everybody else to do something, nothing happens.”, (Ida, OE, High, Can make a difference, in particular when others join).

A low personal norm reflected either indifference and/or a lack of engagement with regard to environmental issues (Indifferent, $n=9$ ), scepticism towards the specific influence of daily transport in relation to the environment (De-emphasisers, $n=6$ ) or general scepticism towards climate change and global warming (Deniers, $n=6$ ). The Indifferent had a low personal norm with regard to environmental issues in general. For them, a lack of engagement in environmental activities appeared to be rubbing off on the area of daily transport:

"I must be honest and say that I don't think a lot about cars [in relation to the environment] (...). We don't talk about it [environmental issues] that much at all.”, (Patrick, PN, Low, Indifferent).

In contrast, the De-emphasisers and Deniers may have a personal norm to act in an environmentally friendly way, but this norm is not activated due to either a lack of knowledge or a higher prioritisation of costs in relation to environmentally friendly choices. The result is - in line with the NAM - a denial/downgrading of the harmful consequences of car use.

The Deniers' stance was generally motivated by a lack of proof based on references to the media: 
"There don't need to be made a lot of changes, I think (...) or as they say in the news, all this about $\mathrm{CO}_{2}$ damaging the atmosphere. It is pure theory, it has not been proven", (Martin, PN, Low, Denier).

or based on personal experiences from daily life:

"Climate change and $\mathrm{CO}_{2}$ and all that actually don't interest me much. They talk about global warming, and you look out the window and there is no sign of it”, (Anna, PN, Low, Denier).

Contrary to the climate change deniers, the De-emphasisers accepted the basic idea of climate change, but questioned transport as being important in that context. While Deniers deny the negative consequences of car use, the De-emphasisers only play down the consequences but deny the personal responsibility for the problem and its solution:

"Well of course cars also make a difference, but I don't think it can be compared with how much $\mathrm{CO}_{2}$ and pollution big industry factories emit at all. I don't think that can be compared at all”, (Nadia, PN, Low, De-emphasiser).

"I don't really believe that I can make a difference unless other people contribute too", (Tom, OE, low, cannot make a difference unless everyone joins).

In line with the last citation, the majority of persons with a low personal norm also expressed a low level of outcome efficacy.

Table 3 shows how ascribed levels of personal norm relate to adolescents' residential location and gender. Adolescents living in rural areas displayed the lowest level of personal norm, whereas all participants living in Copenhagen had a medium or high personal norm. With regard to gender, most females had a medium or high level of personal norm, whereas more than half of the male participants had a low personal norm. Within the group of low personal norm, males were particularly overrepresented among the Unengaged (males: $n=7$, females: $n=2$ ). 
Table 3: Level of personal norm by gender and residential location

\begin{tabular}{llrrrrrrrr}
\hline & \multicolumn{3}{c}{ Level of PN } & \multicolumn{1}{c}{} & & & & \\
& & \multicolumn{1}{c}{ High } & \multicolumn{1}{c}{ Medium } & Low & \multicolumn{2}{c}{ Sum } \\
\hline \multirow{2}{*}{ Gender } & Male & 3 & $12 \%$ & 8 & $32 \%$ & 14 & $56 \%$ & 25 & $100 \%$ \\
& Female & 9 & $36 \%$ & 9 & $36 \%$ & 7 & $28 \%$ & 25 & $100 \%$ \\
\multirow{3}{*}{ Residential location } & Copenhagen & 2 & $33 \%$ & 4 & $67 \%$ & 0 & $0 \%$ & 6 & $100 \%$ \\
& Smaller city & 8 & $26 \%$ & 8 & $26 \%$ & 15 & $48 \%$ & 31 & $100 \%$ \\
& Rural area & 2 & $15 \%$ & 5 & $38 \%$ & 6 & $46 \%$ & 13 & $100 \%$ \\
\hline
\end{tabular}

\subsubsection{Intervention}

As part of their reflections on how to handle transport related $\mathrm{CO}_{2}$ emissions in the future, the adolescents addressed three interrelated sub-themes: type of action, level of action, and implementation strategy.

We identified two different possibilities with regard to type of action: technological developments and behavioural change. Technological developments included further development of vehicles and fuels to make car-use more environmentally friendly. Adolescents for example suggested to further develop electric vehicles to increase the use of sustainable energy sources such as windmills and solar cells.

"If we could produce some electric vehicles, that would be smart, if we could establish some large solar power stations in the Sahara desert and have the electricity delivered here, that would be smart”, (Andreas, Intervention, Type, Technology).

According to the adolescents, this would allow enjoyment of the convenience and comfort provided by the car without potential damage to the environment. Behavioural change included aspects such as changes in mode choice and travel pattern in favour of environmentally friendly modes and was perceived as a necessary, yet much more challenging, solution. Most adolescents mentioned both options.

Level of action involved whether the individual or society had a duty to initiate the relevant behaviour change. Most adolescents emphasised the need and obligation to take action at the societal level. Persons who argued for individual actions were characterised by a higher level of outcome efficacy.

Some Environmentalists argued that since they could not personally close coal-fired power stations, possible areas of influence, such as transport behaviour, should be prioritised. By contrast, some De-emphasisers argued that changes in mode choice at the individual level would make no difference due to the unchanged and significant impact of power stations and other pollutants beyond individual control. 
Adolescents further reflected on possible implementation strategies, and whether or not to base behavioural change on mandatory regulations such as laws and fines, or voluntary engagement facilitated by information, moral obligation, and economic incentives. Although most adolescents were in favour of voluntary engagement, persons with a low personal norm appeared to be more supportive of mandatory regulation than the rest of the adolescents:

"I think it would be smart to make a law about it, how much $\mathrm{CO}_{2}$ people could be allowed to emit (...). People think more about themselves than about $\mathrm{CO}_{2}$ emissions”, (Tom, Intervention, Implementation, Mandatory).

Pragmatists were rather against mandatory regulations and stressed the need for technological solutions:

"In my opinion society should avoid over-regulation (...). Some people may oppose to that (...). Instead, we need to spend money on research (...) and develop well-functioning environmentally friendly cars, electric cars that drive long distances and work, so that people no longer need to choose petrol-cars”, (Ole, Intervention, Implementation, Voluntary).

In addition, Environmentalists were predominately against mandatory regulations but stressed the importance of increasing knowledge and changing norms and attitudes as a basis for behavioural change:

"One can try to change people's attitudes but it would be totally wrong to force people", (Hans, Intervention, Implementation, Voluntary).

"When people don't know why they shall follow a law, they will just pay the fine and become angry with the government”, (Gitte, Intervention, Implementation, Voluntary).

As the examples illustrate, forcing people to behave in a specific way was thought to be counterproductive, resulting in defiant behaviour and a lack of compliance. At the same time the dilemma that short-term individual interests might be prioritised over long-term common goals was acknowledged, leading to the conclusion that some action at the societal level (national as well as international), serving to guide and motivate behaviour change, was necessary. One participant suggested the application of an injunctive norm as a solution to this dilemma: 
"Make it an unwritten rule, so that people would look down upon you if you had three cars, or if you drove the car all the time. So that you would be 'forced' to do it, because you don't want to be looked down upon.”, (Estrid, Intervention, Implementation, Voluntary).

Specific suggestions regarding the societal regulation of individual behaviour, included restrictions on $\mathrm{CO}_{2}$ emission levels, number of cars per family, and no driving on Sundays. Suggestions supporting voluntary behaviour change included incentives such as higher fuel prices, economic bonuses for people behaving sustainably, and lower prices and more efficient public transport and electric cars. In addition, Environmentalists suggested information campaigns focusing on the environmental impact of different activities.

\section{Discussion}

The purpose of this study was to explore the associations drawn by 15-year-old adolescents between daily transport and environmental impact. Based on the data, the NAM appeared as a suitable theoretical framework to explain individual differences in environmental awareness, and whether awareness resulted in environmentally friendly behaviour or not.

In contrast to previous studies focusing on climate changes (e.g. Bostrom, Morgan, Fischhoff \& Read, 1994; Klöckner et al., 2010a), adolescents drew only weak spontaneous associations between own transport behaviour and climate change but mainly focused on household energy saving behaviours. That we avoided explicitly stating our interest in associations between transport behaviour and environmental impact (and thereby possibly biasing the results), may have contributed to this result. The explorative approach of the interviews allowed the adolescents to come up with such associations if relevant for them. Although the associations were weak, we did identify differences regarding pro-environmental awareness, personal norms and related reflections, along with nuanced perspectives of possible strategies to support sustainable transport behaviour.

In contrast to other European studies on young people (Heikkilä, 2014; Kuhnimhof et al., 2012a,b), we could not find any indication that the symbolic-affective functions ascribed to the car are decreasing in the younger generation, but found car status even acknowledged among some of the environmentalists. The same individuals that condemned cars as pollutants on a societal level, appreciated the speed, comfort and status the car offered on an individual level. All adolescents expressed the intention to acquire a driving licence around the age of 18, even if this did not necessarily imply the wish to own a car but simply having the possibility to drive.

Using in-depth interviews as the method of data collection facilitated an understanding of the qualitative aspects of the associations drawn by the adolescents, and thus into the chains of 
reasoning leading to their approach to make environmental transport choices or not. This understanding points towards relevant focus areas in terms of motivating behavioural change or maintaining sustainable aspirations, which policy makers should take up.

Yet, the identified sub-groups of adolescents may require different targeted actions, as suggested by Bamberg (2014) for people at different stages at behaviour change: With regard to Environmentalists, who can be compared with people in the post-actional stage, the main focus should be on positive feedback, moral and social support for their current engagement. To increase their commitment, one should give them the opportunity to promote pro-environmental behaviour, for example by getting involved in the planning of school activities, such as bike to school campaigns and serving as a role model for others.

For Pragmatists, who are closest to the pre-actional stage, it is important to support their exploration of pros and cons of behavioural alternatives. As Pragmatists are willing to engage in pro-environmental behaviour when this brings them personal advantages, these advantages should be made more visible by promoting arguments for the use of the bike and public transport. Such arguments do not need to be restricted to environmental reasons. Arguments mentioned by adolescents in this study include independence from parents, the social function of public transport (in particular trains) and the freedom and exercise gained from cycling. Public transport use among adolescents should additionally be supported by actual improvements. One example are cheap monthly tickets for public transport for this target group, which can serve as a marketing instrument for tying-in customers at an early stage as high public transport prices were often mentioned as a barrier for public transport use.

The Indifferent are at the pre-decisional stage, which means they see no need for behaviour change. For them it would be important to increase their motivation to behave environmentally friendly, for example by increasing their problem awareness, highlighting the consequences of their individual behaviours and increase the perceived ability to change behaviour. Bamberg (2014) additionally suggests making social norms more salient - a strategy that has also been suggested by an Environmentalist in this study. Moreover, high focus should be placed on the reduction of reactance (Bamberg, 2014). Improvements of existing alternatives to the car and the promotion of existing personal advantages may be even more important for this group, but more difficult to achieve. For people with a moral motivation (Environmentalists) it could rather be counterproductive to emphasise personal advantages as this may result in a re-attribution of their own behaviour as not being motivated by an intrinsic moral obligation but by selfish motives. Similarly, Nayum, Klöckner, and Mehmetoglu (2016) suggest that the provision of extrinsic incentives for environmental transport options (i.e. electric cars) may result in a reduced likelihood of activated personal norms. 
Deniers and De-emphasisers may be difficult to reach by arguments as the denial or deemphasing of the environmental threat may be a strategy to avoid negative affect in relation to climate change and the result is an avoidance of information that show the seriousness of the problem. It is thus important that children and adolescents get the chance to verbalise their emotions with regard to climate change and environmental problems, take collective action and develop meaning-and problem-focused strategies, before they need to protect themselves by deemphasising or denying the threat (see Ojala, 2013). Increasing knowledge and perceived behavioural control seems to play a relevant role in that process (see Klöckner et al., 2010b).

When concluding on the influence of location and gender, the sample size and the qualitative nature of the data have to be considered as restricting factors. We found gender and living location associated with environmental awareness, personal norm and the strategies to reduce transportrelated pollution in the future: In line with previous findings (e.g. Loughland et al., 2002, 2003; OECD, 2009; Tuncer et al., 2005) females showed a higher pro-environmental awareness and were more often among the Environmentalists while males were more often among the Indifferent.

The results with regard to residential location are in line with findings for adults (e.g. Berenguer et al., 2005): The associations drawn between daily transport and environmental impact were stronger among adolescents living in Copenhagen, as was their personal norm. The difference between rural and urban adolescents possibly reflects a difference regarding personal experience with transport-related pollution (Weber, 2006) and proximity to problem sites (Gifford \& Nilsson, 2014), as well as greater availability of environmentally friendly alternatives such as buses or bicycles (e.g. Huddart-Kennedy et al., 2009).

Yet, when looking at the actual travel mode choice for the trip to school, we find no major differences between the types of residential location; actually rural pupils in this study walk and cycle a bit more often than their urban counterparts. This is in line with the results from Bogner and Wiseman (1997) who found that rural pupils' behaviours are more environmentally friendly than their respective commitment. As an explanation for this, they suggest a less prominent role of social desirability in terms of environmental issues than in urban areas. That the high personal norm of predominantly (sub)urban Environmentalists does not always translate into sustainable behaviours or intentions, was also observable when talking about future car ownership. Surprisingly, female Environmentalists came up with the most specific visions of their dream car, visions solely based on aesthetic and symbolic qualities that public transport cannot offer and are difficult to bring in line with the high environmental values they expressed. On the one hand, easy access to public transport may trigger more explicit considerations regarding mode choice in families living in cities, thereby increasing their awareness of pros and cons, including 
environmental impact of different choices (e.g. Aldred \& Jungnickel, 2014; Baslington, 2009; Gössling, 2013; Haustein et al., 2009). On the other hand, the urban life-style may also awake the desire to be fashionable and stick out from the mass.

The result that Environmentalists were more in favour of soft measures directed to change attitudes and behaviours on a voluntary basis, while persons with a lower personal norm argued for mandatory measures, may reflect the adolescents' evaluations about what would be most effective in their own case. Environmentalists think that people would act more sustainably if they only knew the extent of the problem better, while Pragmatists and the Indifferents probably know that they would only change behaviour if they were forced to do so as aspects like convenience, status, and freedom associated with the car are valued higher than acting in a sustainable way.

Results indicate the relevance of interventions aiming to increase awareness of environmental impact of daily transport among youth as a first step towards increasing sustainable transport choices in the future. This may be challenging, as transport does not possess obvious aesthetic qualities, like physical attraction or cuteness, which are known to be of importance for public support of an issue (Knight, 2008; Waitt \& Appley, 2014). Therefore, one cannot expect immediate emotionally based support for sustainable transport. More importantly, environmental impact of human behaviour is difficult to comprehend due to its complex and diffuse nature (Marquart-Pyatt et al., 2011) and people's limited likelihood of personal experiences with the consequences (Linden, 2015). The results of this study indicate that this also applies to the specific context of adolescents' daily transport. To overcome these challenges, measures to increase awareness and acceptance of the environmental impact of daily transport should include tangible feedback or evoke strong emotions to make the negative environmental consequences appear urgent and relevant at the individual level in the daily context of the adolescents possibly by simulations as suggested by Weber (2006). Another way of awareness raising and feedback provision is the default integration of $\mathrm{CO}_{2}$ information on different transport choices in travel planners. A good framing of the provided information and a visualisation of saved $\mathrm{CO}_{2}$ emissions that appeals to emotions (e.g. picture of trees equivalents in addition to $\mathrm{CO}_{2}$ mass) are suggested as ways to make the information more graspable and appealing (Waygood, Avineri, \& Lyons, 2012). Information on calories and costs can be added to address additional motivations.

\section{Conclusions and further research}

The results indicate a need for measures to increase adolescents' awareness and acceptance of daily transport as a relevant issue in relation to sustainability. The results also point to the need to address the social dilemma identified in relation to sustainable behaviour, as well as the provision 
of action competences as a lack of perceived behavioural control and outcome efficacy may result in denying and de-emphasising the negative consequences of daily transport.

The study includes a small Danish sample. This means that the generalisation of the results to other groups or countries is restricted. Denmark has a well-established cycling culture (Fact sheet, 2015; Haustein \& Nielsen, 2016) and a well-developed public transport system; both factors may have influenced the results. As Danish adolescents are aware of realistic alternatives to the private car, they may be more aware of the pros and cons of different transport modes including their environmental impact as compared to adolescents in more car-reliant mobility cultures. However, as the weak spontaneous associations between daily transport and environmental impact indicate, this does not seem to be the case. Due to frequent bicycle use in Danish cities, transport-related pollution may be less obvious among the Danish youth, and thus an issue less frequently considered.

In a cycling culture, increasing awareness and providing positive feedback for cycling might decrease the likelihood that adolescents replace cycling by driving as soon that they get licensed. School education can support the process of awareness raising. In Denmark, environmental issues are already addressed as part of the school curriculum, but we suggest focussing more specifically on transport.

More car-reliant cultures may though require different strategies and thus studies investigating the prevalence of the identified pro-environmental norms among subgroups of adolescents in other social and cultural contexts are highly relevant. This also includes deeper knowledge on how environmental norms develop over time and how they relate to other aspects such as sociodemographics, own and relevant others' transport behaviours, and infrastructural and spatial characteristics. Such studies could validate and specify our conclusions and suggestions on how to enhance sustainable travel behaviour based on an early effort in the relevant target groups.

\section{Acknowledgements}

The authors would like to acknowledge the financial support provided by the Danish Agency for Science Technology and Innovation and the Danish Ministry of Transport, Building and Housing.

\section{References}

Ajzen, I. (1991). The theory of planned behavior. Organizational behavior and human decision processes, 50(2), 179-211. 
Ajzen, I., Joyce, N., Sheikh, S., Cote, N.G. (2011). Knowledge and the prediction of behavior: The role of information accuracy in the theory of planned behavior. Basic and Applied Social Psychology, 33, 101-117.

Aldred, R., Jungnickel, K. (2014). Why culture matters for transport policy: the case of cycling in the UK. Journal of Transport Geography, 34, 78-87.

Ali, R., 2014. Rethinking representation: negotiating positionality, power and space in the field. Gender, Place and Culture: A Journal of Feminist Geography, 22 (6), 783-800. 10.1080/0966369X.2014.917278.

Anable, J., Lone, B., Kelay, T. (2006). An evidence based review of public attitudes to climate change and transport behaviour. Final report. The Department for Transport, UK.

Bamberg, S.(2003). How does environmental concern influence specific environmentally related behaviours? A new answer to an old question. Journal of Environmental Psychology, 23, 2132.

Bamberg, S. (2013). Applying the stage model of self-regulated behavioral change in a car use reduction intervention. Journal of Environmental Psychology, 33, 68-75.

Bamberg, S. (2014). Psychological contributions to the development of car use reduction interventions. In T. Gärling et al. (Eds.), Handbook of Sustainable Travel (pp. 131-149). Netherlands: Springer.

Bamberg, S., Hunecke, M., \& Blöbaum, A. (2007). Social context, personal norms and the use of public transportation: Two field studies. Journal of Environmental Psychology, 27 (3), 190203.

Banister, D., Schwanen, T., Anable, J.(2012). Introduction to the special section on theoretical perspectives on climate change mitigation in transport. Journal of Transport Geography, 24, 467-470.

Baslington, H. (2009). Children's perceptions of attitudes towards, transport modes: why a vehicle for change is long overdue. Children's Geographies, 7, 305-322.

Bauman, A., Titze, S., Rissel, C., Oja, P. (2011). Changing gears: bicycling as the panacea for physical inactivity? British Journal of Sports Medicine, 45, 761-762.

Berenguer, J., Corraliza, J.A., Martin, R.(2005). Rural-urban differences in environmental concern, attitudes, and actions. European Journal of Psychological Assessment, 21, 280-238.

Bogner, F. X., \& Wiseman, M. (1997). Environmental perception of rural and urban pupils. Journal of Environmental Psychology, 17 (2), 111-122.

Braun, V., Clarke, V. (2006). Using thematic analysis in psychology. Qualitative Research in Psychology, 3, 7-101. 
Busse, M., Menzel, S. (2014). The role of perceived socio-spatial distance in adolescents' willingness to engage in pro-environmental behavior. Journal of Environmental Psychology, 40, 412-420.

Capstick, S.B. (2013). Public understanding of climate change as a social dilemma. Sustainability, 5, 3484-3501.

Chapman, L. (2007). Transport and climate change: a review. Journal of Transport Geography, 15, 354-367.

Collin-Lange, V. (2012). Socialities in motion: automobility and car cruising in Iceland. Mobilities, 8, 406-423.

Collin-Lange, V. (2014). 'My car is the best thing that ever happened to me': automobility and novice drivers in Iceland. Young, 22, 185-201.

Coogan, M., Nygaard, N., \& Weinberger, R. (2017). Understanding Changes in Youth Mobility, NCHRP 08-36, Task 132. Report prepared for the AASHTO. http://onlinepubs.trb.org/onlinepubs/nchrp/docs/NCHRP08-36(132)_FR.pdf

Collin-Lange, V., Benediktsson, K. (2011). Entering the regime of automobility: car ownership and use by novice drivers in Iceland. Journal of Transport Geography, 19, 851-858.

Connell, S., Fien, J., Lee, J., Sykes, H., Yencken, D. (1999). 'If it doesn’t directly affect you, you don't think about it': a qualitative study of young people's environmental attitudes in two Australian cities. Environmental Education Research, 5, 95-113.

David, Q., Foucart, R. (2014). Modal choice and optimal congestion. Regional Science and Urban Economics, 48, 12-20.

Davison, P., Davison, P., Reed, N., Halden, D., Dillon, J. (2003). Children's attitudes to sustainable transport, research findings No. 174/2003, Scottish Executive Social Research.

Delbosc, A., Currie, G. (2013). Courses of youth licensing decline: a synthesis of evidence. Transport Reviews, 33, 271-290.

De Palma, A., Lindsey, R. (2011). Traffic congestion pricing methodologies and technologies. Transportation Research Part C, 19, 1377-1399.

England, K.V.L. (1994). Getting personal: reflexivity, personality, and feminist research. Professional Geographer, 46, 80-89.

European Commission (2011). White paper. Roadmap to a single European transport area Towards a competitive and resource efficient transport system. http://eurlex.europa.eu/LexUriServ/LexUriServ.do?uri=COM:2011:0144:FIN:EN:PDF

Fact sheet (2015). http://www.modelcenter.transport.dtu.dk/english/tu/hovedresultater 
Fine, M., Weis, L., Weseen, S., Wong, L. (2000). For whom? Qualitative research, representations, and social responsibilities. In N. K. Denzin \& Y. S. Kincoln (Eds.), Handbook of Qualitative Research (pp. 107-131). Thousand Oaks, CA: Sage.

Frändberg, L., Vilhelmson, B. (2011). More or less travel: personal mobility trends in the Swedish population focusing gender and cohort. Journal of Transport Geography, 19, 1235-1244.

Fyhri, A., Hjorthol, R., Mackett, R.L., Fotel, T.N., Kyttä, M. (2011). Children’s active travel and independent mobility in four countries: Development, social contributing trends and measures. Transport Policy, 18, 703-710.

Gaskell, G. (2000). Individual and Group Interviewing. In M. W. Bauer \& G. Gaskell (Eds.), Qualitative Researching with Text, Image and Sound (pp. 38-56). London: Sage.

Gatersleben, B., Appleton, K.M. (2007). Contemplating cycling to work: attitudes and perceptions in different stages of change. Transportation Research Part A, 41, 302-312.

Girod, B., van Vuuren, D.P., de Vries, B. (2013). Influence of travel behavior on global CO2 emissions. Transportation Research Part A, 50, 183-197.

Giuliano, G., Dargay, J. (2006). Car ownership, travel and land use: a comparison of the US and Great Britain. Transportation Research Part A, 40, 106-124.

Gössling, S. (2013). Urban transport transitions: Copenhagen, city of cyclists. Journal of Transport Geography, 33, 196-206.

Haustein, S., Klöckner, C.A., Blöbaum, A. (2009). Car use of young adults: the role of travel socialization. Transportation Research Part F, 12, 168-178.

Haustein, S., \& Nielsen, T. A. S. (2016). European mobility cultures: A survey-based cluster analysis across 28 European countries. Journal of Transport Geography, 54, 173-180.

Huddart-Kennedy, E., Beckley, T.M., McFarlane, B.L., Nadeau, S. (2009). Rural-urban differences in environmental concern in Canada. Rural Sociology, 74, 309-329.

Hysing, E., Frändberg, L., Vilhelmson, B. (2014). Compromising sustainable mobility? The case of the Gothenburg congestion tax. Journal of Environmental Planning and Management, 58 (6), 1058-1075. DOI: 10.1080/09640568.2014.912615.

Jovchelovitch, S., Bauer, M.W. (2000). Narrative Interviewing. In M. W. Bauer \& G. Gaskell (Eds.), Qualitative Researching with Text, Image and Sound (pp. 57-74). London: Sage.

Klöckner, C. A., Beisenkamp, A., \& Hallmann, S. (2010a). Klimawandel aus Sicht 9-bis 14jähriger Kinder-Emotionen, Bewältigungsressourcen und allgemeines Wohlbefinden. Umweltpsychologie, 14, 121-142.

Klöckner, C. A., Beisenkamp, A., \& Hallmann, S. (2010b.) Wie motivieren klimawandelbezogene Emotionen Kinder zum Klimaschutz? Ein Arbeitsmodell, Umweltpsychologie, 14, 143-159. 
Klöckner, C. A., \& Matthies, E. (2004). How habits interfere with norm-directed behaviour: A normative decision-making model for travel mode choice. Journal of Environmental Psychology, 24 (3), 319-327.

Knight, A.J. (2008). “Bats, snakes and spiders, Oh my!!” How aesthetic and negativistic attitudes, and other concepts predict support for species protection. Journal of Environmental Psychology, 28, 94-103.

Kopnina, H., Williams, M. (2012). Car attitudes in children from different socio-economic backgrounds in the Netherlands. Transport Policy, 24, 118-125.

Kuhnimhof, T., Buehler, R., Dargay, J. (2011). A new generation. Travel trends for young Germans and Britons. Transportation Research Record, 2230, 58-67.

Kuhnimhof, T., Buehler, R., Wirtz, M., Kalinowska, D. (2012). Travel trends among young adults in Germany: increasing multimodality and declining car use for men. Journal of Transport Geography, 24, 443-450.

Kuhnimhof, T., Zumkeller, D., Chlond, B. (2013). Who made peak car, and how? A breakdown of trends over four decades in four countries. Transport Reviews: A Transnational Transdisciplinary Journal, 33, 325-342.

Levine, D.S., Strube, M. (2012). Environmental attitudes, knowledge, intentions, and behaviors among college students. The Journal of Social Psychology, 152, 308-326.

Linden, S.V.D. (2015). The social-psychological determinants of climate change risk perceptions: towards a comprehensive model. Journal of Environmental Psychology, 41, 112-124.

Line, T., Chatterjee, K., Lyons, G. (2010). The travel behaviour intentions of young people in the context of climate change. Journal of Transport Geography, 18, 238-246.

Line, T., Chatterjee, K., Lyons, G. (2012). Applying behavioural theories to studying the influence of climate change on young people's future travel intentions. Transportation Research Part $D, 17,270-276$.

Loughland, T., Reid, A., Petocz, P. (2002). Young people's conceptions of environment: a phenomenographic analysis. Environmental Education and Research, 8, 187-197.

Loughland, T., Reid, A., Walker, K., Petocz, P. (2003). Factors influencing young people’s conceptions of environment. Environmental Education Research, 9, 3-19.

Marquart-Pyatt, S.T., Shwom, R.L., Dretz, T., Dunlap, R.E., Kaplowitz, S.A., McCright, A.M., Zahran, S. (2011). Understanding public opinion on climate change: a call for research. Environment: Science and Policy for Sustainable Development, 53, 38-42.

McLeroy, K. R., Bibeau, D., Steckler, A., Glanz, K. (1988). An ecological perspective in health promotion programs. Health Education Quarterly, 15, 351-377. 
Murtagh, N., Gatersdleben, B., Uzzell, D. (2014). Self-identity threat and resistance to change: evidence from regular travel behaviour. Journal of Environmental Psychology, 32, 318-326.

Nayum, A., Klöckner, C. A., Mehmetoglu, M. (2016). Comparison of socio-psychological characteristics of conventional and battery electric car buyers. Travel Behaviour and Society, 3, 8-20.

Newmann, P., Kenworthy, J., 2011. Peak car use': understanding the demise of automobile dependence. World Transport Policy and Practice, 17, 31-42.

OECD (2009). Green at fifteen? How 15-year-olds-perform in environmental science and $\begin{array}{lllll}\text { geosciences } & \text { in } & \text { PISA } & \text { Retrieved } & \text { from }\end{array}$ http://www.oecd.org/about/publishing/corrigenda.htm

Ojala, M. (2012). How do children cope with global climate change? Coping strategies, engagement, and well-being. Journal of Environmental Psychology, 32, 225-233.

Ojala, M. (2013). Coping with climate change among adolecents: Implications for subjective well-being and environmental engagement. Sustainability, 5, 2191-2209.

Otto, S., Kaiser, F.G. (2014). Ecological behavior across the lifespan: why environmentalism increases as people grow older. Journal of Environmental Psychology, 40, 331-338.

Owen, S. (2000). Commentary. 'Engaging the public': information and deliberation in environmental policy. Environment and Planning, 32, 1141-1148.

Paw, J.B., Doncke, V., Petegen, P.V. (2011). Adolescents' environmental worldview and personality: An explorative study. Journal of Environmental Psychology, 31, 109-117.

Prochaska, J. \& DiClemente, C. (1983). Stages and processes of self-change in smoking: toward an integrative model of change. Journal of Consulting and Clinical Psychology, 5, 390-395.

Rose, G. (1997). Situating knowledges: positionality, reflexivities and other tactics. Progress in Human Geography, 21, 305-320.

Schwartz, S. H. (1977). Normative influences on altruism. Advances in Experimental Social Psychology, 10, 221-279.

Schwartz, S. H., \& Howard, J. A. (1981). A normative decision-making model of altruism. Altruism and Helping Behavior, 189-211.

Sigurðardóttir, S.B., Kaplan, S., Møller, M., Teasdale, T.W. (2013). Understanding adolescents’ intentions to commute by car or bicycle as adults. Transportation Research Part D, 24, 1-9.

Sigurðardóttir, S.B., Kaplan, S., Møller, M. (2014). 'Now or later?` Understanding adolescents' intentions to obtain a driving license and own a car. Transport Research Arena 2014, Paris.

Stanley, J.K., Hensher, D.A., Loader, C. (2011). Road transport and climate change: stepping off the greenhouse gas. Transportation Research Part A, 45, 1020-1030. 
Sælensminde, K. (2004). Cost-benefit analyses of walking and cycling track networks taking into account insecurity, health effects and external costs of motorized traffic. Transportation Research Part A, 38, 593-606.

Toth, N., Little, L., Read, J.C., Fitton, D., Horton, M. (2013). Understanding teen attitudes towards energy consumption. Journal of Environmental Psychology, 34, 36-44.

Tranter, P., Sharpe, P. (2012). Disney-Pixar to the rescue: harnessing positive affect for enhancing children's active mobility. Journal of Transport Geography, 20, 34-40.

Tuncer, G., Ertepinar, H., Tekkaya, C., Sungue, S. (2005). Environmental attitudes of young people in Turkey: effects of school type and gender. Environmental Education Research, 11, 215-233.

Underwood, S.K., Handy, S.L., Paterniti, D.A., Lee, A.E. (2014). Why do teens abandon bicycling? A retrospective look at attitudes and behaviors. Journal of Transport and Health, $1,17-24$.

Uitto, A., Juuti, K., Lavonen, J., Byman, R., \& Meisalo, V. (2011). Secondary school students' interests, attitudes and values concerning school science related to environmental issues in Finland. Environmental education research, 17 (2), 167-186.

Valentine, G. (1999). Being seen and heard? The ethical complexities of working with children and young people at home and at school. Philosophy and Geography, 2, 141-155.

Van Dijk, E., Parks, C.D., Van Lange, P.A.M. (2013). Social dilemmas: the challenge of human cooperation. Organizational Behavior and Human Decision Processes, 120, 123-124.

Van Lange, P.A.M., Joireman, J., Parks, C.D., Van Dijk, E. (2013). The psychology of social dilemmas: a review. Organizational Behavior and Human Decision Processes, 120, 125-141.

Verplanken, B., Walker, I., Davis, A., Jurasek, M. (2008). Context of change and travel mode choice: Combining the habit discontinuity and self-activation hypothesis. Journal of Environmental Psychology, 28, 121-127.

Waygood, E.O.D., \& Avineri, E. (2016). Communicating transportation carbon dioxide emissions information: Does gender impact behavioral response? Transportation Research Part D: Transport and Environment, 48, 187-202.

Waygood, O., Avineri, E., \& Lyons, G. (2012). The role of information in reducing the impacts of climate change for transport applications. In T. Ryley, \& L. Chapman (Eds.), Transport and Climate Change (pp. 313-340). Bingley, UK: Emerald Group.

Waitt, G., Appleby, B. (2014). 'It smells disgusting': plaiting up kangaroo for a changing climate. Continuum: Journal of Media \& Cultural studies, 28, 88-100.

Weber, E.U. (2006). Experience-based and description-based perceptions of long-term risk: why global warming does not scare us (yet). Climate Change, 77, 103-120. 
Wegman, F., Zhang, F., Dijkstra, A. (2012). How to make more cycling good for road safety? Accident Analysis and Prevention, 44, 19-29.

Wray-Lake, L., Flanagan, C., Osgood, D.W. (2010). Examining trends in adolescents' environmental attitudes, beliefs and behaviors across three decades. Environment and Behavior, 42, 61-85. 